\title{
Ontological co-belonging in Peter Sloterdijk's spherological philosophy of mediation
}

Thomas Sutherland

In her recent book Imaginal Politics, Chiara Bottici remarks upon 'the privileged attention that, at least since Plato, philosophers gave to end of life over other experiences of it - and, most notably, over its beginning. ${ }^{1}$ This is an important observation and provocation. After all, it is in the death of Socrates that Western philosophy finds its founding myth. Plato rationalizes Socrates' impending demise at the hands of the Athenian city-state by declaring philosophy to be 'nothing other than dying, and being dead', presenting philosophy as a practice of death, a yearning toward the state of incorporeal intellectual contemplation only truly achievable once the immortal soul has been sundered from the encumbrance of its mortal body, orienting itself toward a 'thought unalloyed, alone and by itself. ${ }^{2}$ In the death of Socrates, writes Jean-Luc Nancy, 'the event of sacrifice proper ... the actual putting to death, merely punctuates and lays open the process and the truth of a life that is itself sacrificial through and through', exposing the demands of a truly philosophical life defined by the renunciation of all corporeal exigency. ${ }^{3}$

Surely the most prominent figuration of death within philosophy though comes courtesy of Martin Heidegger, for whom our certain demise marks the ultimate horizon toward which we project ourselves (the 'finitude of temporality'), forming a crucial component of the authentic and primordial time of anticipatory resoluteness. ${ }^{4}$ Bottici challenges this Heideggerian perspective, insisting that it is birth, rather than death, which constitutes our truly primordial experience, 'since we can be beings-toward-death only because we are beings-after-birth' $(I P, 69) .{ }^{5}$ In taking such a viewpoint, reorienting ourselves in relation to birth rather than death,

it immediately comes to light that we have arrived on the scene literally to-gether with an-other human being. Even before being born, we were accompanied. Communication begins in the womb and never stops thereafter. Only death will put an end to it. At the very beginning, it is a prelinguistic form of communication, but precisely for this reason it is perhaps an even stronger one based on the sharing of the same body $(I P, 69)$.

Being-toward-death imprints upon our lives the telos of mortal finitude, our impending demise the horizon that stands before us, marking the irreducible singularity of our existence, for death is indeed the only event in our life when we are completely monadic' (IP, 68). Being-after-birth then might conversely disclose an originary coupling or sociality, what Bracha Ettinger describes as a matrixial encounter-event 'between the subject-to-be and the becoming-mother', that compromises any such claim to singularity. ${ }^{6}$

It is this sense of co-belonging, inaugurated prior to birth, that Peter Sloterdijk attempts to give ontological significance in the first volume of the Spheres trilogy, asserting that investigating humans philosophically means, first and foremost: examining paired structures', with the mother and child being emblematic of this dyadic structuration. ${ }^{7}$ In focusing upon the human being's forced entry into the world (her or his thrownness or facticity), rather than the anticipation of their demise, Sloterdijk attempts to reconfigure the Heideggerian fundamental ontology such that Being-in-the-world is necessarily a state of Being-with-others, grounded in a yearning to replicate an originary 'biune' co-belonging. ${ }^{8}$ It is for this reason that he aligns his own philosophical approach with the concerns of media theory, which he describes (somewhat unusually) as the study of 'the togetherness of something with something in something' $(S I, 542)$, viewing communication as grounded in the desire to construct and belong to a space 
Thomas Sutherland, 'Ontological co-belonging in Peter Sloterdijk's spherological philosophy of mediation', Paragraph. 40 (2): $133-152$. http://www.euppublishing.com/doi/abs/10.3366/para.2017.0222

wherein one might replicate the comfort, security and immediacy of the womb. It is this notion upon which I will focus in this article. I will begin by examining the way in which Sloterdijk repositions and expands upon several of Heidegger's claims (most importantly, the anticipatory resoluteness of Beingtoward-death, and the primordial spatiality of Dasein), connecting this to the concerns of contemporary media theory, before concluding by contesting the political value of an ontology premised upon an exclusionary conception of belonging.

\section{Being-after-birth and the primordial spatiality of Dasein}

Heidegger's take on phenomenology, Jean-Paul Sartre once commented, inaugurates the interiorization of death within the core of subjectivity, such that it is no longer the great unknowable which limits the human; it is the phenomenon of my personal life which makes of this life a unique life - that is, a life which does not begin again'. ' Indeed, our anticipation of our own death is inscribed by Heidegger as a basic condition of the potentiality-for-Being that Dasein assigns to itself, and thus of Dasein's existence in the world also. 'With death, Dasein stands before itself in its ownmost potentiality-for-Being ... Its death is the possibility of no-longer being-able-to-be-there' $(B T, 294)$. The authentic existence of Dasein is inextricable from the world into which it is thrown, Being-in-the-world belonging to 'the essential content of [Dasein's] understanding of Being' $(B T, 118)$. The ecstatic temporality of this facticity (viz. the temporalization of world-time) is in turn only possible on the basis of our Being-toward-death, the anticipation of which facilitates the temporal unity of Dasein (its openness to the possibility of that wherein it is thrown) and hence the primordial, authentic experience of time.

The question that needs to be asked, however, is why Heidegger does not seem to take entirely seriously his own description of Dasein as 'that entity which is "between" birth and death' (BT, 425, my emphasis). Why does Heidegger so emphatically prioritize the event of death over that of birth? It is precisely this apparent absence that Sloterdijk seeks to redress, identifying Being-in-the-world as that state of existence in which one is alienated from the gestational coupling of mother and child, 'having to cling to the earth's crust and praying to gravity - beyond any womb or shell' (SI, 23). The human being is not an isolated creature, Sloterdijk suggests; rather, he or she is essentially social, and his or her Being-in-theworld is unavoidably communal and spatial in nature, an ongoing attempt to replicate the comfort and security of their uterine existence. Individuals

inevitably suffer a form of mental resettlement shock when the first bubble bursts, an existential uprooting: they come out of their infantile state by ceasing to live completely under the shadow of the united other and thus starting to become inhabitants of an expanded psycho-sociosphere' (SI, 54).

World disclosure is thus grounded not so much in the looming recognition of one's eventual death, but instead in the painful awareness of a state of co-belonging to which one can never return. Humans are ultimately 'spheric beings that only master life's hazards in the world's openness in the interplay with their augmenters, companions and pursuers' $(S I, 478)$ - always mediated, always exteriorized.

Accordingly, for humans to reside in the world, 'it is initially in spaces that have opened for them because, by inhabiting them, humans have given them form, content, extension and relative duration' $(S I, 46)$. Humans do not simply belong to the world into which they are thrown; they rather construct this belonging for themselves, shaping their environment in order to imitate the now-inaccessible habitation from which they originated. ${ }^{10}$ The cutting of the umbilical cord, which 'coincides with the imposition of forgoing the comfortably immediate blood communion with the mother and accepting the more hazardous and variable circumstances of oral nourishment and external embraces' (SI, 393-394) symbolizes the rupture that both founds and fetters human sociality. To belong, without remainder, to 
Thomas Sutherland, 'Ontological co-belonging in Peter Sloterdijk’s spherological philosophy of mediation', Paragraph. 40 (2): $133-152$. http://www.euppublishing.com/doi/abs/10.3366/para.2017.0222

regain the augmentative, insulating biune coupling of mother and child, is the impossible imperative that drives the impulse to dwell, constructing a sphere of care within a world that one is forced to inhabit. The human being, over the course of its existence, remains agonized by 'the memory of a different havingbeen-inside, and by the anticipation of a final being-enclosed'. ${ }^{11}$ For Sloterdijk, writes Marie-Eve Morin, 'human existence primordially takes on the character of exodus, removal, and relocation'. ${ }^{12}$

It is in Being and Time that Sloterdijk views a latent theory of primordial spatiality 'wedged subthematically' $(S I, 342)$, his quest thus being to recover and expand this embryonic conceptualization of 'an essential tendency towards closeness' $(B T, 140) .{ }^{13}$ Indeed, for Heidegger the state of Being-in-the-world is inherently spatial, for it is in space that one encounters the ready-to-hand. This essential spatiality of Dasein, however, cannot be reduced to what Sloterdijk describes as 'the multi-millennial rule of container physics and metaphysics', whereby humans are integrated 'more or less automatically into an encompassing nature as cosmos' $(S I, 335,338)$, leaving them as merely ontic entities residing within-theworld, presuming that we connaturally belong to and dwell within the world, rather than actively having to construct such enclosure. The spatiality of Dasein, as always exceeding presence-at-hand, 'cannot signify anything like occurrence at a position in "world-space", nor can it signify Being-ready-to-hand at some place'; rather, it is in the world 'in the sense that it deals with entities encountered within-the-world, and does so concernfully and with familiarity' $(B T, 138)$. Dasein, and its Being-in-the-world, is not simply within space, for space is exactly that which is disclosed by said Being-in-the-world. ${ }^{14}$

More specifically, though, Heidegger declares that 'Dasein is essentially de-severance' $(B T, 143)$, and it is this characteristic that marks its fundamental spatiality. The bringing-close of this de-severing has nothing to do with objective distance, which remains present-at-hand, but instead is the particular modality of concern by which the remoteness of the ready-to-hand is eliminated (whilst at the same time also revealing the very possibility of remoteness and distance, opening up the space in which entities become near and far, accessible and inaccessible to Dasein). 'The circumspective de-severing of Dasein's everydayness reveals the Being-in-itself of the "true world" - of that entity which Dasein, as something existing, is already alongside' (BT, 141). Dasein is always spatial inasmuch as it is thrown into the world, and it is this quality of de-severance (along with its complementary existentiale of directionality) that, in effect, allow it to make use of this world, to open up a space in which entities may be encountered as ready-tohand.

In Sloterdijk's estimation, Heidegger never properly develops his conceptualization of de-severance and directionality, and as a result, misses the opportunity to explore 'the multi-significant universes of existential spaciousness' (SI, 340) afforded by these existentialia. Central to his project is the contention that Heidegger's existential analytics of time is 'rooted in a corresponding analytics of space' $(S I, 333)$ that has been consistently overlooked, even by Heidegger himself. The reason why this question of spatiality is so important for Sloterdijk is that it challenges Heidegger's usual presentation of Dasein as an isolated, singular entity, whose authentic existence lies in a temporality that seems to exceed not only the ontico-existentiell world-space in which entities are made ready-to-hand, but also the ontologicoexistential spatiality discussed above, insofar as the finitude of Dasein's existence is circumscribed by its Being-toward-death. ${ }^{15}$ Heidegger's refusal to adequately grapple with the problem of spatiality 'leaves behind a lonely, weak, hysterical-heroic existential subject that thinks it is the first to die, and remains pitifully uncertain of the more hidden aspects of its embeddedness in intimacies and solidarities' (SI, 341). Concomitantly, the seemingly vital claim that 'the world of Dasein is a with-world [Mitwelt]', such that 'Being-in is Being-with Others' $(B T, 155)$ remains largely misprized.

\section{The intractable trauma of facticity}


Thomas Sutherland, 'Ontological co-belonging in Peter Sloterdijk's spherological philosophy of mediation', Paragraph. 40 (2): $133-152$. http://www.euppublishing.com/doi/abs/10.3366/para.2017.0222

Sloterdijk is by no means the first or only philosopher to make note of this lacuna within Being and Time. Perhaps most notably, Nancy pays considerable attention to the tacit theories of communication and community buried within the Heideggerian corpus:

[i]f the world is Mitwelt, shared world, Being insofar as it is "in the world" is constitutively beingwith, and being-according-to-the-sharing. The originary sharing of the world is the sharing of Being, and the Being of the Dasein is nothing other than the Being of this sharing. ${ }^{16}$

It is this notion of 'an originary or ontological "sociality"' $(I C, 28)$ - whereby the singularity of one's existence is dependent upon the singularity of that of others also - which we might otherwise describe as a primordial and spatial belonging that remains latent within Heidegger's philosophy. ${ }^{17}$ This sociality is defined not by communion (in which singularities would all participate in a superior totality), but rather by communication, a sharing of finitude consisting in the dislocation and in the interpellation that reveal themselves to be constitutive of being-in-common - precisely inasmuch as being-in-common is not a common being' $(I C, 29)$. Communication is not a bond, nor an exchange; it is instead a compearance one's mere appearance (and according recognition of finitude) as a singularity amongst other singularities. Refusing any appeal to a common substance or being immanent to the social body, Nancy $(I C, 29)$ posits communication as 'the constitutive fact of an exposition to the outside that defines singularity'.

This torsion of interiority and exteriority - the formation of subjectivity in in its factical relation to Others - is exactly that which Sloterdijk likewise attempts to procure from Heidegger's account of spatiality, observing that moods (the existentialia that continuously colour Dasein's Being-in-the-world) are 'initially never the affair of individuals in the seeming privacy of their existential ecstasy; they form as shared atmospheres - emotionally tinted totalities of involvement - between several actors who tint the space of closeness and make room for another in it' (SII, 138). Humans are never truly isolated, individual, or self-sufficient, for '[o]nly the ideologia perennis that drifts in the mainstream of individualistic abstraction speaks of the unaccompanied single person' $(S I, 478) .{ }^{18}$ Essentially, 'Being with Others belongs to the Being of Dasein' $(B T, 160)$.

Particularly crucial here is the previously discussed concept of Being-toward-death, which for Sloterdijk 'means not so much the individual's long march into a final solitude anticipated with panicstricken resolve' as it does 'the circumstance that all individuals will one day leave the space in which they were allied with others in a current, strong relationship' (SI, 48). If the human being is a political animal (following the Aristotelian formulation), inasmuch as she or he necessarily belongs to a community (the nominal polis), then this possibility is in turn only open because the human being is also 'the animal that must expect and survive separation from those closest to it' $(S I I, 160)$ - mourning as a survival mechanism becomes the necessary condition for community. To become an individual within a society composed of individuals 'thus means preparing oneself to be abandoned with the predecease of the irreplaceable other' (SII, 153), psychically safeguarding oneself from the trauma of this separation (which replicates in some manner the loss of biunity that accompanies birth). The ego 'first assumes a self-referential shape through the anticipation of being orphaned and widowed, and posits itself as deserted and deserting' (SII, 155156).

The novelty of Sloterdijk's approach here is that he transforms the concept of Being-toward-death such that it is no longer concerned primarily with the anticipation of and anxiety regarding one's own death (which would situate Dasein, in the last instance, as an 'I' isolated from all Others), but rather, with that of the deaths of those around them (such that the singularity and finitude of the 'I' is instead registered in its inevitable separation from these Others), providing insulation against the trauma of this rupture (and in turn replicating their first confrontation with abandonment - the existential uprooting of their birth into the world that inaugurates their Being-in-the-world): '[b]ecause the ego-forming 
Thomas Sutherland, 'Ontological co-belonging in Peter Sloterdijk's spherological philosophy of mediation', Paragraph. 40 (2): $133-152$. http://www.euppublishing.com/doi/abs/10.3366/para.2017.0222

expectation of abandonment is of an essentially anticipatory nature, it protects those who have braced themselves for being left alone some day from irreparable separation disasters' $(S I I, 156)$. To belong to the world, in this context, is not only to be in (i.e. thrown into) the world, but also to construct the world in such a way that one is protected against the anguish of death - hence the importance of mourning, memorializing the dead.

It is in this respect that Sloterdijk attempts to remedy the cursory treatment of spatiality within Being and Time: rather than focusing on the anticipatory resoluteness of Dasein (her or his impending solitude), he shifts his attention instead to the spaces via which Dasein attempts to belong within the world. The figure of the psycho-social sphere, so central to this project, would seem to derive primarily from a single passage in Being and Time:

[w] hen Dasein directs itself towards something and grasps it, it does not somehow first get out of an inner sphere in which it has been proximally encapsulated, but its primary kind of Being is such that it is always "outside" alongside entities which it encounters and which belong to a world already discovered $(B T, 89)$.

For Sloterdijk, this sphere of Being-outside-of-itself is produced through the transference of 'early spatial experiences to new places, and primary movements onto remote locations' $(S I, 12)$. In other words, the spheres that humans construct for themselves - remembering that such spheres are always constructed 'not according to free choice ... but under preexisting, given and handed-down conditions' $(S I, 48)$ - are a form of de-severence, enabling access to that which is remote, allowing us to safely approach and internalize externalities, or to distance ourselves from those that we cannot. An authentic, ecstatic existence can thus paradoxically only occur through these processes of protection and insulation - an enclosure. Belonging to the world involves either protecting ourselves from the Other, or making it in some way belong to us.

\section{Mediacy and immediacy}

Through his conceptualization of the spheric interiorities through which humans insulate and domesticate themselves, Sloterdijk aims to restore to contemporary philosophy its feeling for absolute localization', redefining the forgetfulness of Being as 'an obstinate willful ignorance of the mysterious place of existence' $(S I, 27)$. Such forgetfulness has been exacerbated by the dislocative, disorienting and deracinating processes of globalization, a movement of spatial projection from the microsphere to the macrosphere (and then in turn to a spherical plurality) which 'opposes homesickness for the unchanging and harboring and follows the pull towards what is unattached, has never before existed, and was promised from afar' $(S I I, 41)$, substituting the thought of Being with that of a purified becoming. By reconceptualizing Dasein as that Being for which Being-in-the-world means fundamentally Being-withothers, he attempts to identify a mode of communication or mediation that precedes transmission - that is, a conception of mediation as not only Being-with-others, but being between them; belonging to a space that is cohabited with others. Ultimately, Sloterdijk asks, ' $[w]$ hat are media theories but suggestions of ways to explain the how and the whereby of the connection between different existents in a shared ether?' $(S I, 542)$, proposing a proxemic understanding of mediation that has little in common with the dominant twentieth-century models of communication, which he regards as wholly inadequate for reflecting the ways in which human bonding (and the concomitant construction of symbolic environments) opens up the de-severed space in which communication tout court becomes possible.

Throughout his work, Sloterdijk is castigatory toward Jacques Lacan's 'tragically presumptuous' theorem of the mirror stage, which he argues 'cannot overcome its dependence on the cosmetic or egotechnical household inventory of the nineteenth century' (SI, 197), extrapolating out a universalized 
Thomas Sutherland, 'Ontological co-belonging in Peter Sloterdijk's spherological philosophy of mediation', Paragraph. 40 (2): $133-152$. http://www.euppublishing.com/doi/abs/10.3366/para.2017.0222

hypothesis regarding psychoanalytic ego-formation from a mediatic contingency. ${ }^{19}$ In the first volume of the Spheres trilogy, a rather different narrative is put forward: rather than the 'salutary imago' ${ }^{20}$ of the ideal unity of the ego emerging from a misrecognition by the subject (this moment of alienation marking the subject's entry into the Imaginary order), the subject's perceived wholeness is instead derived from 'the early dyadic communication between the child and its augmenter-companion, which, aside from its prenatal supplementation media is usually the mother' (SI, 535). It is through the 'vocal, tactile, interfacial and emotional games of resonance' $(S I, 535)$ between mother (or other such figure) and child that the latter is reminded, for better or worse, of the originary biunity that preceded his or her birth. The desire for dwelling, and with it a longing to belong absolutely, as we have already seen, is thus understood as a ceaseless quest by the factical subject to regain this seemingly lost wholeness. ${ }^{21}$

Although the traditional conceptual armature of the sender-receiver communication model becomes significant 'when the concern is to learn something about something', this transmission of information, Sloterdijk contends, is fundamentally preceded by the spatial openness of Dasein, whereby 'being-in or being-in-something must take "place"' (SII, 136). To focus on the process by which information is transmitted is to neglect the space in which this process occurs, not only in the sense of the technical medium that acts as the channel of transmission, but also more broadly of the environment to which all communicating actors (whether human or non-human) belong, this mere fact of belonging effecting a mutual co-constitution that facilitates symbolic communication (which is in turn a surrogate for the non-symbolic, pre-natal matrixial communication between mother and child). If the act of birth marks the origin of an ontological openness to the world, whereby 'that which is close and innermost is abandoned to an inescapable tearing-open by the distant' $(S I, 326)$, first exposing the human being to the distinction between interiority and exteriority, then it is the spheric insulation of these constructed spaces that maintains this disclosure of entities in their distance, whilst concurrently providing the capacity for us to circumspectively enact a bringing-close that allows 'the conquest of remoteness' ( $B T$, 140).

What chiefly separates Sloterdijk's account from other kindred thinkers is his conception of the sphere as necessary psycho-social protection against 'the external, the foreign, the fortuitous' (SI, 55), disclosing the human being's exteriority in such a manner that the shock of their thrownness might be overcome. ${ }^{22}$ These spheres, as Morin writes, 'separate the human from the pressure of the environment, allow him $[s i c]$ to develop in a non-adaptative way and prepare the world-opening of the human, that is, prepare his sensibility for what is either spatially or temporally remote' $(C H A, 84)$. Perhaps the closest connection we might establish then is with Freud, who famously speculates that writing 'was in its origin the voice of an absent person; and the dwelling-house was a substitute for the mother's womb, the first lodging, for which in all likelihood man still longs, and in which he was safe and felt at ease'. ${ }^{23}$ It is the medium of telephony that, for Freud, would seem to finally suture this void, offering us the once seemingly-fantastic capacity to achieve presence across distance - a bringing-close without remainder, evoking our gestational dwelling.

But Sloterdijk is not satisfied to merely associate this longing for closeness with the medium of the mother's voice (which would tie it to a specifically linguistic register of desire); he instead brings it back to 'a fluidal communion in the medium of blood' $(S I, 295)$, noting that blood is 'the first material between two individuals who will one day - when they become modern people - speak on the telephone'. There is an 'experience', a bonding through the pre-objective medium of 'the With' (SI, 356), that precedes the child's entry into the world, and yet directly conditions the mode in which it will live in and belong to the world. ${ }^{24}$ 'The experience of the first container situation is tied to early evidence of being genuinely harbored in correspondence with the co-living' (SII, 199), constituting a mediated 'With' that precedes the perceived wholeness of the 'I'. 
Thomas Sutherland, 'Ontological co-belonging in Peter Sloterdijk's spherological philosophy of mediation', Paragraph. 40 (2): $133-152$. http://www.euppublishing.com/doi/abs/10.3366/para.2017.0222

\section{A life lived in media}

The Stoic philosopher Seneca makes a distinction between two kinds of commonwealth to which a philosopher concurrently belongs:

One is great and truly common to all, where gods as well as men are included, where we look not to this corner or that, but measure its bounds with the sun. The other is that in which we are enrolled by an accident of birth - I mean Athens or Carthage or some other city that belongs not to all men but only a limited number. ${ }^{25}$

We have here a perfect description (echoed centuries later by Saint Augustine) of the traditional philosophical outlook, transcending the facticity of one's physical birth (including the community into which one is born) in order to reach a sphere of necessary truth unfettered by such contingency; dividing our subjectivity between an ideal existence and its ancillary factical counterpart. The goal of such philosophy, writes Sloterdijk, is 'ascetic and solitary research into the truth about the round whole, the complete, the unanimous, the One' $(S I I, 18) .{ }^{26}$

Sloterdijk's focus upon the decentred reciprocal resonance of the 'symbiotic space' $(S I, 52)$ of prenatal communication, and the human being's attempts to reconstruct this intimacy in the facticity of their mortal existence, is intended to subvert the philosophical image of a 'beautifully rounded' (SI, 99) orb (exemplified by the Eleatic One), underscoring instead the contingency and instability of the enclosures in which we envelop ourselves. Describing media theory as 'a general science of visitability of something by something in something' $(S I, 31)$, Sloterdijk brings to the fore the necessarily temporary and precarious state of belonging by which the human being maintains the world in which they reside. Tacitly highlighted here also though is a particular difficulty that we face in media theory: specifically, the disbelief that there could possibly be, in John Durham Peters' words, 'such a thing as a media-free life'. ${ }^{27}$ Indeed, media theory is founded upon the facticity of belonging to the world, and thus of finding ourselves trapped within the contingencies of mediation. It remains immanent to the historically-variable existentialia of shared human existence, and as a consequence, acts as a corrective to the dogmatic, eternalizing impulses of the philosophical logos.

In a similar fashion, the Spheres project represents, as Nigel Thrift argues, 'an attempt to move philosophy into new domains', to allow 'the world to speak back', bringing philosophy into contact with domains generally regarded as un-philosophical. ${ }^{28}$ Thrift rightly connects this project to the so-called 'non-philosophy' of François Laruelle, who consistently seeks to foreground 'the relative autonomy of the regional', refusing to allow philosophy to totalize and domesticate the regional knowledges, discourses and practices that lie outside its ambit. ${ }^{29}$ Yet where Laruelle proposes a conception of the human being stripped of all anthropological ornamentation, a human-in-human that does not belong to the world, Sloterdijk's subversion of philosophy operates instead by reintegrating philosophy into the world that it typically tries to transcend, emphasizing a fundamental belonging in which the philosophical logos is grounded. It does this by founding human experience in mediation: we belong to the world, and we are beings-in-the-world, but only because we have constructed this belonging ourselves, in a process of continual augmentation and exteriorization (through which interiority is constituted). Indeed, 'anyone who presumes to speak of humans without mentioning their inspirators and intensifiers, or their media, which amount to the same, has missed the topic through their very approach' $(S I, 42)$. It is only in death that the human being is finally separated from this world, and the communication on which it is founded.

In contrast to Laruelle's approach, which seeks a perspective outside of the vicious circles of mediation, but does so only by abandoning itself to a mystical immanence, registering a finitude that seemingly forecloses all possibility of communication (and thus falling back into the typically philosophical denigration of communication that extends back at least as far as Parmenides' critique of 
Thomas Sutherland, 'Ontological co-belonging in Peter Sloterdijk's spherological philosophy of mediation', Paragraph. 40 (2): $133-152$. http://www.euppublishing.com/doi/abs/10.3366/para.2017.0222

doxa), there is appeal in the way that Sloterdijk constantly emphasizes the constituent sociality of subjectivity, its necessary Being-with-others, whilst simultaneously noting the facticity of any such belonging. ${ }^{30}$ Reading Heidegger against himself, identifying a subterranean current of spatial collectivity that flows throughout his work. Sloterdijk implores us 'to become involved with the monstrousness of the external' (SI, 629), and to locate ourselves within this monstrousness in which we are born, rather than transcending this space in favour of the formal perfection of philosophical ideality. Philosophy must be interpreted as a discursive construct, a coping mechanism (against the trauma of birth and the fear of death) that itself belongs to the world, rather than providing an external perspective upon the world after all, 'philosophy could not have erected its sublime constructions without the mandate of its carrier culture' (SI, 56).

At the same time though, for all that he critiques Heidegger's persistent valorization of the solitary human subject who in the final instance can never truly belong the world, one must wonder whether Sloterdijk's solution, predicated upon the claim that '[b]efore a Dasein assumes the character of being inthe-world, it already has the constitution of being-in' (SI, 541), does anything more than substitute the trauma of detachment from an originary biune coupling for the anxiety of an anticipated ultimate demise. After all, in Sloterdijk's media theory, all worldly communication appears to be treated as inadequate in relation to the 'uterine immediacy' $(S I, 394)$ of this gestational co-belonging. By arguing that subsequent to her or his birth, Dasein will remain 'a de-coupled, de-siblinged and uprooted residual subject' (SI, 397), Sloterdijk posits a matrixial immediacy that, in its inevitable loss, renders subjectivity congenitally incomplete, and the mediacy of communication a mere shadow of its former wholeness. Although the ontological significance of the solitude of death is conspicuously downplayed, the everydayness of Dasein (its existence between birth and death) is still marked as inferior to its conjunctive genesis, 'the constant placenta-mediated exchange of blood between mother and child', this blood being 'not only the blood of the one', but also forming 'the first medial "bond" between the dyadic partners interlocked in bipolar intimacy' (SI, 294-295).

It is telling that Sloterdijk explicitly connects this relationship to the 'pneumatic relation' $(S I, 49)$ between God and Adam, established when the former breathed the breath of life into the latter's nostrils. In the 'primal catastrophe' that is the subsequent expulsion from Eden, this biune bubble (the prelapsarian Adamic covenant) bursts, and humanity is forced into new spheres of its own construction, opening it up to an outside where 'freedom is only granted along with foreignness, indifference and plurality' (SI, 51-52). The biune relationship is thus in the end just another analogue for the divine communion - an immediacy without remainder - that was sundered in the Fall of humankind from paradise, making this 'loss of innocence' $(S I, 77)$ an essential aspect of thought. ${ }^{31}$ Of course, there is nothing especially problematic in the suggestion that human communication and intersubjectivity are constituted by a certain inexorable opacity - opining that communication 'involves a permanent kink in the human condition' is a commonplace within media theory today. ${ }^{32}$ But what makes Sloterdijk's account somewhat problematic is the way that it tacitly treats the encounter with alterity that grounds our Being-in-the-world as an unfortunate (albeit necessary) consequence of our existential facticity. The sheltered communion of the womb (the purity of the With) comes to seem preferable to the uncertain mediations of everydayness, and in particular, the 'open, cold and silent sky' of postmodern existence, wherein our institutions (the remains of the welfare state, mass-media, etc.) can only furnish a pale 'imitation of the now impossible, imaginary spheric security' $(S I, 24-25) .{ }^{33}$

\section{Rootedness and the politics of exclusion}

When we treat human beings as 'beings-after-birth,' argues Bottici, 'it is not only the essentially social nature of the psyche that comes to light but also the fact that there is a fundamental openness to the other' $(I P, 69)$. The frustrating aspect of Sloterdijk's project is that whilst he regards the ecstatic state of 
Thomas Sutherland, 'Ontological co-belonging in Peter Sloterdijk's spherological philosophy of mediation', Paragraph. 40 (2): $133-152$. http://www.euppublishing.com/doi/abs/10.3366/para.2017.0222

'a life-in-the-midst-of-lives' (SI, 542) to be the authentic spatial horizon of human existence, in constantly judging the originary belonging of gestational enclosure as superior to the openness of our everyday existence, he ends up venerating a particular social ideal: specifically, that of the sphere as a space closed off as far as possible to the alterity of the outside world, fostering an immediacy of communication grounded in a shared identity. ${ }^{34}$ At times he explicitly describes this belonging or enclosure in terms of a 'rootedness' or 'authochthony' (SI, 342) that has been forgotten in philosophy's blindness to place and space. Rather than peddling false hopes of an all-inclusive global communion, Sloterdijk suggests, we must remember that 'viewed from any point in our lifeworld, the vast majority of individuals, languages, works of art, commodities and galaxies remain an unassailable outside world, by necessity and forever' (SI, 76). Philosophy must renounce its hubris and exclusivity, it must become willing 'to praise transference and to refute loneliness', resisting the temptation to transcend its own factical origins, but it may only do this through the recognition that 'the limits of [our] capacity for transference are the limits of [our] world' $(S I, 13)$.

Such a perspective is of course in distinct contrast to the typically post-structuralist emphasis upon our responsibility to the irreducible alterity of our world. Indeed, Sloterdijk writes, ' $\mathrm{w}]$ hat is necessary after becoming weary of post-structuralist infinitisms is to work on an ontology of the finite, inchoate, monstrous world' (SII, 128), emphasizing the determinacy of place over the indeterminacy of an unknowable future. Opposed to what he views as the false openness of globalization, Sloterdijk contends that philosophy must now be 'a matter of working anew through the tension between autochthony ( $a b$ ovo and in terms of the community) and release (in terms of death or the infinite)' (SI, 342), foregrounding the everydayness of Dasein as a Being between birth and death. Rather than actually uniting the planet in a kind of global village, an organic wholeness, globalization represents for Sloterdijk instead the extirpation of spherical insulation: the modern man is 'the idiot of the cosmos; he has sent himself into exile and expatriated himself from his immemorial security in self-blown bubbles of illusions into a senseless, unrelated realm that functions on its own' $(S I, 23)$.

On the one hand, there is surely value in Sloterdijk's concern that the networking of the globe (a process far more advanced now than when this book was first written) has led to a 'morphological anarchy' in which 'individuals and associations of subjects can no longer produce any complete world', such that they 'shrink to isolated depressive points transplanted into random surroundings' (SI, 73). It would seem fruitless to deny that one of the more troubling effects of the all-encompassing expansion and 'industrious hysteria' (SI, 26) of the global market is its dismantling of the social institutions, commitments, and solidarities that once defined the polis, and the sense of community and identity that they afforded. The socio-technical acceleration of our everyday existence, combined with increasingly precarious and mobile labour conditions leave us spatio-temporally dislocated and epistemically disoriented. We find ourselves as atomized individuals largely unable to form the strong attachments upon which a true civil society is founded. In this context, the frustratingly common theoretical valorization of nomadism would seem rather perverse - a cosmopolitanism that is 'usually no more than the philosophical superstructure of cheap flights between European and American capitals' (SII, 386), telling us more about the privileges of academia than the ontology of human existence.

On the other hand though, Sloterdijk's paranoia regarding the 'responsibility-free connivance' (SI, 76) of the zeitgeist in its obsession with openness to the infinitude of the Other has quite worrying normative implications. By conceptualizing mediation in terms of enclosure and visitation, viewing spherical insulation as an imperfect but necessary means of approaching the perfect immediacy of the blood communion between mother and child, Sloterdijk conceives of sociality as an inevitably exclusionary yearning to belong within a metaphorical 'bell jar of purpose' $(S I, 57)$ insulated from those externalities that it cannot bring under its dominion. A sphere 'is infringed upon from the start by the non-interior world, and must perpetually assert itself against the provocation of the outside, restore itself 
Thomas Sutherland, 'Ontological co-belonging in Peter Sloterdijk’s spherological philosophy of mediation', Paragraph. 40 (2): $133-152$. http://www.euppublishing.com/doi/abs/10.3366/para.2017.0222

and increase' $(S I, 46)$. It is not surprising then that Sloterdijk has such reservations regarding the way that globalization forces us to constantly take into account 'the distant other, the stranger to one's container' (SII, 938), for this global de-severence is precisely that which would render such exclusion impossible. The intimacy of transference (and thus sociality) demands an identity rooted in place, and this in turn demands an immanent investigation into the conditions of possible transference. There is no pure sociality, but only a transference bound by place and identity.

At a time when individuals are urged to express their authentic selves (whilst also being prompted to perpetually better themselves), the proposition that it is less important for people to know who they are than where they are' $(S I, 27)$ might act as a useful rejoinder - a kind of spatialized existentialism (thrownness preceding essence). The importance of Sloterdijk's provocations cannot be understated, and as Stuart Elden remarks, '[w]e would repay Sloterdijk badly if we simply listed his errors, staked out our differences, and disputed his claims. We should also engage with his ideas, follow his paths, and take inspiration from his tireless intellectual energy and breadth of engagements' ${ }^{35}$ But surely there is a risk that his overt anti-cosmopolitanism falls into one of the most worrying contemporary trends: the reassertion of a jingoistic and often explicitly racialized politics of exclusion mounted in response to (often quite reasonable) concerns regarding the socially corrosive power of a globalized market.

Feeding into what Wendy Brown describes as a 'fear related to the porousness of modern nationstates and to the exposure of vulnerable individuals and deracinated communities to the vicissitudes of global forces', Sloterdijk gives ontological and world-historical significance and justification to this retreat into parochial nationalism. ${ }^{36} \mathrm{He}$ writes in his controversial rejoinder to Heidegger's 'Letter on Humanism' that humans 'are self-fencing, self-shepherding creatures', and his attempt at a spherological media theory largely attempts to prop up this claim as an essential attribute of human existence. ${ }^{37}$ Therefore, whilst Sloterdijk is surely correct in diagnosing what he calls an age of 'epidemic shell disturbances' (SI, 331), at a time when we are witnessing the reinstatement of national borders in the name of a virulent right-wing populism, one must ask what normative value an account of mediation that exalts the immediacy of an enclosed communion actually holds. Can a fundamental ontology of cobelonging (and re-localization) be reconciled with a politics of inclusion? 
Thomas Sutherland, 'Ontological co-belonging in Peter Sloterdijk's spherological philosophy of mediation', Paragraph. 40 (2): $133-152$. http://www.euppublishing.com/doi/abs/10.3366/para.2017.0222

\section{${ }^{1}$ Chiara Bottici, Imaginal Politics: Images Beyond Imagination and the Imaginary (New York: Columbia} University Press, 2014), 68; hereafter $I P$.

${ }^{2}$ Plato, The Last Days of Socrates, translated by Hugh Tredennick and Harold Tarrant (London: Penguin, 2010), 95, 98.

${ }^{3}$ Jean-Luc Nancy, A Finite Thinking, edited by Simon Sparks (Stanford, CA: Stanford University Press, 2003), 56.

${ }^{4}$ Martin Heidegger, Being and Time, translated by John Macquarrie and Edward Robinson (Oxford and Cambridge, MA: Blackwell, 1962), 379; hereafter BT.

${ }^{5}$ On the topic of birth as diametrical counterpart to death, see Hannah Arendt's perennially influential The Human Condition (Chicago, IL: The University of Chicago Press, 1998). We might also note the following writings, all of which pay close attention to the elision of birth in Heidegger: Christina Schües, 'The Birth of Difference', Human Studies 20:2 (1997); Adriana Cavarero, Stately Bodies: Literature, Philosophy, and the Question of Gender, translated by Robert de Lucca and Deanna Shemek (Ann Arbor, MI: University of Michigan Press, 2002); and Anne O’Byrne, Natality and Finitude (Bloomington and Indianapolis, IN: Indiana University Press, 2010).

${ }^{6}$ Bracha Ettinger, 'Weaving a Woman Artist With-in the Matrixial Encounter-Event', Theory, Culture \& Society 21:1 (2004), 76.

${ }^{7}$ Peter Sloterdijk, Spheres Volume I: Bubbles - Microspherology, translated by Wieland Hoban (Los Angeles, CA: Semiotext(e), 2011), 477-478; hereafter SI. For a concise overview of Sloterdijk's overall corpus (which remains beyond the scope of this article), see Jean-Pierre Couture, Sloterdijk (Cambridge and Malden, MA: Polity, 2016). ${ }^{8}$ This notion of 'biunity', an originarily dyadic union 'that can only last on the basis of a developed bipolarity', involving 'mututal referentiality and intertwined freedom from which neither of the primal partners can be removed without canceling the total relationship' (SI, 42-43), is pivotal to Sloterdijk's account both of gestation and the prelapsarian relationship between God and Adam.

9 Jean-Paul Sartre, Being and Nothingness: An Essay on Phenomenological Ontology, translated by Hazel Barnes (New York: Washington Square Press, 1984), 532.

${ }^{10} \mathrm{~A}$ sphere is 'the place that humans create in order to have somewhere they can appear as those who they are' $(S I, 28)$.

${ }^{11}$ Peter Sloterdijk, Spheres Volume II: Globes - Macrospherology, translated by Wieland Hoban (Los Angeles, CA: Semiotext(e), 2014), 198; hereafter SII.

${ }^{12}$ Marie-Eve Morin, 'The Coming-to-the-World of the Human Animal' in Sloterdijk Now, edited by Stuart Elden (Cambridge and Malden, MA: Polity, 2012), 87; hereafter CHA.

${ }^{13}$ On this focus upon spatiality in Sloterdijk, see also Marijn Nieuwenhuis, 'Taking Up the Challenge of Space: New Conceptualisations of Space in the Work of Peter Sloterdijk and Graham Harman', continent. 4:1 (2014).

${ }^{14}$ Existence 'creates its own surrounding space through which and in which it appears' (SI, 57).

15 'Inhabitation in spheres cannot be explicated in detail ... as long as existence [Dasein] is understood primarily in terms of a supposedly natural inclination towards loneliness' (SI, 340-341).

${ }^{16}$ Jean-Luc Nancy, The Inoperative Community, translated by Peter Connor, Lisa Garbus, Michael Holland, and Simona Sawhney (Minneapolis, MN: University of Minnesota Press, 1991), 103; hereafter IC.

${ }^{17}$ For an examination of the relevance of Nancy's philosophy of Being-with for media theory, see Sybille Krämer, Medium, Messenger, Transmission: An Approach to Media Philosophy, translated by Anthony Enns (Amsterdam: Amsterdam University Press, 2015), 48-54.

${ }^{18}$ Rather than remaining enchanted by our attachments to our fellow humans, we live today within 'the phantasm of an intimate sphere with a single inhabitant, namely that particular individual' (SI, 205). The philosophical responsibility for this ideology supposedly lies with Jean-Jacques Rousseau, who 'was the inventor of the friendless human, who could only conceive of the augmentative other as either a direct maternal nature or a direct national totality', furnishing us with an image of 'the human without protective spirit, the individual without an amulet, the self without a space' (SI, 385-386).

19 'Only in a mirror-saturated culture could people have believed that for each individual, looking into one's own mirror image realized a primal form of self-relation’ (SI, 197). 
Thomas Sutherland, 'Ontological co-belonging in Peter Sloterdijk's spherological philosophy of mediation', Paragraph. 40 (2): $133-152$. http://www.euppublishing.com/doi/abs/10.3366/para.2017.0222

${ }^{20}$ Jacques Lacan, Écrits, translated by Bruce Fink (New York and London: W.W. Norton \& Company, 2006), 92.

${ }^{21}$ In the context of psychoanalysis, we might note the similarities here to Didier Anzieu's conceptualization of the 'skin-ego', although Anzieu explicitly rejects the characterization of mother and child as a symmetrical (i.e. non-hierarchical) dyad; see The Skin-Ego, translated by Naomi Segal (London: Karnac Books, 2016).

${ }^{22}$ The notion of media qua environment is probably first explicitly thematized by Marshall McLuhan. On this topic, see Ursula K. Heise, 'Unnatural Ecologies: The Metaphor of the Environment in Media Theory',

Configurations 10 (2002).

${ }^{23}$ Sigmund Freud, 'Civilization and Its Discontents' in The Freud Reader, edited by Peter Gay (New York and London: W.W. Norton \& Company, 1989), 737.

24 'The With is the first thing that gives and lets things be. If 1 have what it takes to turn from an Also into an ego, it is not least because the With has let me sense the place in which I have begun to find a rooting as an augmentable creature' (SI, 357).

${ }^{25}$ Seneca, Moral and Political Essays, edited and translated by John M. Cooper and J.F. Procopé (Cambridge: Cambridge University Press, 1995), 175.

${ }^{26}$ The metaphysical image of the orb qua One is not equivalent to that of globalization, which Sloterdijk argues in its current form is not at all a process of unification; it is rather a foaming, in which individual bubbles are not absorbed into a single, integrative hyper-orb, as in the metaphysical conception of the world, but rather drawn together to form irregular hills' $(S I, 71)$. This concept is explored further in the third volume of the Spheres trilogy: Peter Sloterdijk, Spheres Volume III: Foams - Plural Spherology, translated by Wieland Hoban (Los Angeles, CA: Semiotext(e), 2016).

${ }^{27}$ John Durham Peters, The Marvelous Clouds: Toward a Philosophy of Elemental Media (Chicago, IL: The University of Chicago Press, 2015), 45. See also Mark Deuze, 'Media Life', Media, Culture \& Society 33:1 (2011).

${ }^{28}$ Nigel Thrift, 'Peter Sloterdijk and the Philosopher's Stone' in Sloterdijk Now, edited by Stuart Elden (Cambridge and Malden, MA: Polity, 2012), 143.

${ }^{29}$ François Laruelle, Principles of Non-Philosophy, translated by Nicola Rubczak and Anthony Paul Smith (London: Bloomsbury, 2013), 47.

${ }^{30}$ What Laruelle offers is not a media theory in any sense; it is rather a theory of non-mediation, of a unilateral and irreversible determination of philosophy by the real. In order to achieve this, however, he must wholly disrupt the communicative, dialogic function of philosophy, the radical human being remaining unsullied by the philosophical logos that would situate her or him as a Being-in-the-world. Regarding all communication and exchange as transcendence, alienating us from the radical immanence of our ordinary, lived existence, the end result is a silent, mystical indifference to the world.

${ }^{31}$ Sloterdijk views modernity as humanity's (mistaken) extrication of itself from the safety of 'traditional theological and cosmological narratives' $(S I, 25)$.

${ }^{32}$ John Durham Peters, Speaking into the Air: A History of the Idea of Communication (Chicago, IL: The University of Chicago Press, 1999), 29.

${ }^{33}$ Our increasingly sophisticated astronomical knowledge from the seventeenth century onward has 'provided increasing evidence that mankind is towered above on all sides by monstrous externalities that breathe on it with stellar coldness and extra-human complexity' $(S I, 23)$.

${ }^{34}$ We might wonder whether Sloterdijk's argument perpetuates, in a quite literal manner, what Luce Irigaray describes as 'the infinite nostalgia for that first home' - a desire for the One-All, the perceived sameness, selfpresent identity of the womb that the philosophical (and patriarchal) logos transmutes into a system of symbolic exchange. An Ethics of Sexual Difference, translated by Carolyn Burke and Gillian C. Gill (Ithaca, NY: Cornell University Press, 1993), 49.

${ }^{35}$ Stuart Elden, 'Worlds, Engagaments, Temperaments' in Sloterdijk Now, edited by Stuart Elden (Cambridge and Malden, MA: Polity, 2012), 16.

${ }^{36}$ Wendy Brown, Edgework: Critical Essays on Knowledge and Politics (Princton, NJ: Princeton University Press, 2005), 10 . 
Draft version - please do not cite

Final version published as:

Thomas Sutherland, 'Ontological co-belonging in Peter Sloterdijk’s spherological philosophy of mediation', Paragraph. 40 (2): $133-152$. http://www.euppublishing.com/doi/abs/10.3366/para.2017.0222

${ }^{37}$ Peter Sloterdijk, 'Rules for the Human Zoo: a response to the Letter on Humanism', Environment and Planning D: Society and Space 27:1 (2009), 25. With its quasi-Nietzschean allusions to 'breeding' and genetic engineering, this article caused widespread dismay when first published in Germany. 